\title{
Two Suggestions toward Teaching Methodologies of Chinese Paintings in the Contemporary Context
}

\author{
Sha Zhuo \\ Guangzhou University \\ School of Fine Arts \& Design \\ Guangzhou, China \\ 793622242@qq.com \\ Meishu Lin \\ Guangzhou University \\ School of Fine Arts \& Design \\ Guangzhou, China \\ 496922562@qq.com
}

\author{
Xinzhe Yao \\ Guangzhou Academy of Fine Arts \\ Guangzhou, China \\ youlanqiangu@163.com
}

\author{
Ting Cao \\ Guangzhou University \\ School of Fine Arts \& Design \\ Guangzhou, China \\ 184393025@qq.com
}

\begin{abstract}
To discusses the problem and predicament of Chinese painting education in the context of cultural shock. We use the combination of theory and practice to investigate and study this problem. In regards to the issues arising from the education, there are two suggestions to be proposed. We should encourage teachers to train students on their ability of identifying and interpreting paintings as well as enhance their theoretical knowledge. In addition, the teachers should urge students to broaden their horizons by visiting art galleries and museums as well as exploring resources online
\end{abstract}

Keywords-Chinese Painting; Ink and Water Painting; Teaching

\section{INTRODUCTION}

It is well known that Chinese painting, as one of the most treasured wealth of traditional culture, has received lots of attentions. Thus, Chinese painting education has always been emphasized as well. In the era with highly developed information, Chinese painting education is confronted with enormous challenges, including the impact of multiculturalism and foreign cultures. In addition, the doubts towards our own culture also have a negative impact on Chinese painting education. Finding out a better way to cope with these dilemmas and pressure and be able to sustain long-term growth have become key issues for Chinese painting scholars to consider.

\section{Issues ARISING FROM ChINESE PAINTING EDUCATION} AND RELATED ANALYSIS

A. Conflicts and Separation of 'Traditional Chinese Painting' and Contemporary Ink and Water Painting in Arts Education

Mr. Yu Li, the translator of Chinese Painting: A Pictorial History mentioned that when the study of Western painting started evolving into Humanities, especially in the places where arts concepts are comparatively advanced, its modern and contemporary parts are widely recognized and accepted. Why did the Chinese painting history still stay in its original position which belongs to Paleology? And why is Chinese painting history still a part of traditional scholars' interests, rather than be promoted to the modern and leading-edge knowledge?[1] This is an awkward situation. Students, teachers and many people in the society still consider Chinese painting study is part of Paleology; and only the contemporary ink and wash paintings belongs to modern arts. This misunderstanding rooted in lots of people, which also results in the lack of theoretical and practical teaching toward Chinese painting education.

Chinese paintings are often treated differently in international and domestic exhibitions. Comparing to the domestic arts market, Chinese paintings would receive more attentions from international arts market. Chinese scholars insisted on the opinions that contemporary ink and wash paintings cannot surpass the traditional ink. as well as wash paintings that were completed before 18 century, in regards to the techniques and cultural deposits; meanwhile, they cannot 
have continuous innovations or bring forth the new through the old. Thus, Chinese paintings started declining.

Some other scholars also have reflected on this issue. For instance, Mr. Li opined that the reason why Chinese painting still belongs to Paleology is closely related to the study methods of Chinese paintings. He believed that "Chinese traditional scholars often conduct researches on Chinese by studying it as a part of Literature, Philosophy and History to seek for meanings of life and human relationships... thus, it would be inevitable for painting to be mixed up with Literature and Philosophy. And, it will lose its deserved position in society”.[2] Chinese paintings is closely related to Literature and Philosophy, which has already been deeply rooted in people's minds. Being separated from the current society, traditional ink and water painting would be unlikely to arouse the sympathetic responses of the young generations. Without the ancient social society and ancient Chinese painting concepts, it would be very difficult for the young generations to understand paintings' meanings or aesthetics of artistic conception expressed in traditional ink and water paintings.

\section{B. Other Related Issues}

In addition, there are some other common issues. Firstly, weak theoretical knowledge often holds students back. In the current education in the academy of fine arts, arts major have been divided into two approaches of teaching: theoretical and practical. In the meantime, students are assigned to different faculties to learn practical theories with distinct focuses as well as the traditional theoretical literature education.

The students majoring in Chinese painting education mainly do research on Chinese painting techniques, but lack the knowledge of Chinese painting criticism and Chinese painting history in their undergraduate stage. Insufficient theoretical knowledge impedes them from discovering Chinese painting techniques. Some students even started working on their so-called artistic creations without sufficient theoretical understandings. It has caused their artworks to lack of spiritual background and meanings; yet, their works are full of formalism. Also, this issue also led to the insufficient creativity among a lot of students.

Secondly, certain teachers are in the habit of employing only one criterion to evaluate students. This has made students to lose their independent thinking and problem-solving abilities. With such teaching methods, the students' artworks will always present the same style and techniques as their teachers' work. To some extent, this would be more like imitation and short of individualism.

\section{DISCUSSION OF RELATED TEACHING METHODS}

\section{A. Formal Analysis: Train on Students' Ability of Identifying and Interpreting Paintings}

In regards to the issues mentioned above, here are some suggestions for discussion. Firstly, in my opinion, we should encourage learning from the western tradition of formal analysis in identifying and understanding paintings. Meanwhile, it is also highly recommended to have more contents of identifying and interpreting painting in practical teaching.
In most universities and colleges, it is common to find painting techniques occupying most of the teaching contents in Chinese painting education plan. On the contrary, the training on identifying and interpreting painting is neglected. In other words, teachers rarely explain the symbolic meanings, the content of paintings as well as their social functions during the painting imitation process, which is the 'fatal' negligence for the visual arts.

In fact, this also goes against the appreciation approaches, historical meanings and social functions of Chinese paintings in its historical developments. Chinese paintings always focus on how to use brush to sketch the lines and the skills of chapping, rubbing, dotting and dying, which had its peak time during the era of Mi's style of water and ink painting landscape. The earliest Chinese paintings, two silk paintings unearthed in Mawangdui, Changsha, Hunan, which made use of neat ink lines to draw and blend with certain colors, has been regarded as the most legitimate painting in the later centuries. Chinese painters always put emphasis on lining and take advantage of lining as the main tool to describe and present their paintings. However, some other artists choose to study how to destroy the completeness of the single lines, which is deviated from the mainstream idea. Nevertheless, they cannot be separated from the formal analysis of paintings and symbolic meanings the artists try to present.

However, Chinese painting teachers always ignore this basic question during the teaching process. They do not interpret the painting's content, conduct formal analysis, research on the symbolic meaning or show students the method of copying drawings by following the painting meanings. In the contrary, they asked students to imitate directly, which would be difficult for students to understand the painting's contents, especially at their first time seeing the painting. Therefore, the paintings would only be imitated on a a superficial basis without their "souls". Indeed, technique is the most significant factor in traditional painting. Nevertheless, emphasizing too much on forms will deviate from the dialectical attitudes toward technique form; such as the image theories of traditional painting and some classic theories. The reason why Chinese paintings could make progress constantly is that artists during the past dynasties put more attentions on 'breaking down' and 'creation' of forms. Spirit and rhyme, elegance and unconventionalism is the guarantee for quality, as well as the soul and core of Chinese paintings. Only if you could understand the theories and criteria of traditional paintings and apply them to the contemporary Chinese painting education entirely, as well as create the 'The Theory of Image' and 'Theory of Six Principles of Painting' of our time rather than follow blindly, then Chinese painting can be revolutionized and evolved.

In addition, the approaches of appreciating Chinese paintings are also important to guide artists on artwork creation. Professor Wen C. Fong provided a detailed analysis of methods of appreciating narrative paintings and landscape paintings in Beyond Representation: Chinese Painting and Calligraphy $8^{\text {th }}$ $14^{\text {th }}$ Century.[8] He also discussed the changes and developments of visual languages toward Chinese landscape paintings from 8th century to 18th century in Summer Mountains: The Timeless Landscape. As written by Mr. Tan in 
Introduction of The Timeless Landscape, Professor Fong uses the 'Three-distance' composition method presented in Shosoin as the foundation to analyze how people use moving views and parallel perspectives to manifest Landscape paintings in Song Dynasty. [4]It is obvious that contemporary artists also use imaging analysis methodology to interpret Chinese paintings, which proves that interpretation of painting is particularly important, especially for Chinese panting itself. I also agree with Mr. Wu's 'Original State' theory that we need to understand the painting in its original creation environment so that we could have a better understanding of regional culture, perceptions and comprehensions.[5][6]

\section{B. Taking Advantage of New Media to Broaden Students' Horizons}

I also believe that teachers should learn to take advantage of new media and platform emerging in the current society, and integrate them into teaching activities. Furthermore, they should encourage students to visit arts galleries and museums and make full use of the online resources to broaden horizons. Student should have greater exposures to substantial amount of different paintings, including both Chinese and western artworks.

Due to the historic issues of modern history, lots of Chinese paintings were lost overseas; for instance, Xia Gui's Twelve Scene Landscape Map in art gallery of Nelson-Atkins, or Zhi Wen's Chinese, active first half of the 13th century Meeting between Yaoshan and $\mathrm{Li} \mathrm{Ao}$, and Liang Kai's Lakeside Troubadour Map Page in Metropolitan Museum of Art in New York, etc. The lack of artwork resources has become the main element of affecting researchers in early times. Limited experience and narrow perceptions made theories incomplete and inaccurate. However, with the fast growth of new media industry, online libraries and virtual art galleries started emerging. By using these resources, we could have the same experience of attending exhibitions in real art galleries; sometimes we could even have a more clear view to paintings, which is good for imitation. It is suggested that teachers should encourage students to browse online resources, imitate paintings, broaden horizons by comprehensive analysis and improve their abilities of identifying, interpreting and imitating paintings.

Here is an example. A student asked me how to use the middle section of a brush to draw water waves and how water waves drawn by painters from the past could be full of changes. I was intrigued by the question, which made me recall an article in Masterpieces of Early Chinese Painting and Calligraphy in American Collections complied by Shanghai Museum. There was a similar question mentioned in that article, written by Professor Wen C. Fong as well. It stated that "Mr. Gong Qi, a deceased calligraphy appraiser, made a comparison of handwriting between Yuan Dong and Zhenqin Yan. Yan's handwriting dominated the Late Tang Dynasty. By using the methods, like holding the brush with five fingers and moving brush point vertically, Yan could maintain the high quality of his work as well as keep his focus while creating, so he reached a higher level to express his skills and feelings freely. Chinese calligraphy and landscape painting both are based on images. From the zoomed pictures with details, we could find out how
Mr. Dong uses calligraphy method to paint branches and water waves in his artworks"[3].[7]

At that very moment, the hidden meanings of the article have finally come to light. By showing the student the two painting pictures and the article, I taught him to understand them and also shared my opinions. After such experience, the student started to comprehend the icons and artistic conceptions of landscape paintings in his later study. Also, he began to create his first landscape painting based on his understanding of brush skills. It is believed that the best way to expose you to the knowledge of identifying and interpreting paintings is by visiting more art galleries and museums, utilizing their online resources, reading more books and attending more exhibitions.

\section{SUMMARY}

The current education is going through a unique time with rapid developments and provided with overwhelming amount of resources. In order to re-engineer the teaching method, defend the history and promote the international status of Chinese paintings, it is essential for us to integrate the emerging trends with education. I believe that two suggestions mentioned above could provide the most useful and abundant teaching contents so that we could establish a better knowledge frame. In addition, training students to have global visions will help them discover new approaches to develop Chinese painting by taking advantage of the available technologies. This will hopefully correct the misunderstanding that 'ink and wash painting' and 'Chinese painting' are out-dated, which is the current view by many international groups. Emphasize should be placed on both aspects; otherwise, the artworks will either lack creativity and meanings or have a limited outlook. Thus, I think Chinese paintings would have new breakthroughs and prosperous developments in the future, only if these two suggestions could be applied at the same time.

\section{REFERENCES}

[1] James Cahill, In Chinese Painting: A Pictorial History,SDX Joint Publishing Company,2014

[2] James Cahill, In Chinese Painting: A Pictorial History,SDX Joint Publishing Company,2014

[3] Masterpieces of Early Chinese Painting and Calligraphy in A merican Collections complied, Edc, Shanghai Museum, PEKING UNIVERSITY PRESS,pp136

[4] Tan Shengguang,The Timeless Landscape,in Summer Mountains :The Timeless Landscape, Wen C. Fong,, Shanghai Book and Painting Press,2017

[5] WenC.Fong,"DeconstructingParadigmsinSungandYuanPainting:Lifeafte rtheDeathofMasteringRepresentation".

[6] WenC Fong ,Toward a Structural Analysis of Chinese Land-scape Painting.Art Journal. 1969

[7] Yong He, Teaching Analysis of Pen and Ink in Chinese Painting Art Creation, 2015 3rd International Conference on Education Reform and Management Innovation, 2015

[8] WenC.Fong.BeyondRepresentation:ChinesePaintingandCalligraphy,8th14thCentury. . 1992 